\title{
Dose- and time-dependent effects of oral octopamine treatments on the sucrose responsiveness in stingless bees (Melipona scutellaris)
}

\author{
Sofía I. Mc $\mathrm{CABE}^{1}$, Marco W. Benetoli Ferro ${ }^{2}$, Walter M. FArInA ${ }^{1}$, Michael HrnciR ${ }^{2,3}$ \\ ${ }^{1}$ Laboratorio de Insectos Sociales, Departamento de Biodiversidad y Biología Experimental, IFIBYNE-CONICET. \\ Facultad de Ciencias Exactas y Naturales, Universidad de Buenos Aires, Pabellón II, Ciudad Universitaria, \\ C1428EHA, Buenos Aires, Argentina \\ ${ }^{2}$ Faculdade de Filosofia, Ciências e Letras de Ribeirão Preto, Departamento de Biologia, Universidade de São Paulo, \\ Avenida Bandeirantes, 3900, Ribeirão Preto, SP CEP: 14040-901, Brazil \\ ${ }^{3}$ Laboratório de Ecologia Comportamental, Departamento de Ciências Animais, Universidade Federal Rural do \\ Semi-Árido, Avenida Francisco Mota, 572, Mossoró, RN CEP: 59625-900, Brazil
}

Received 23 November 2015 - Revised 22 February 2016 - Accepted 10 March 2016

\begin{abstract}
Biogenic amines modulate physiological responses and, consequently, the behaviour of animals. Here, we present the first pharmacological approach to evaluate the influence of octopamine (OA) in stingless bees (Apidae, Meliponini), a group of highly eusocial bees distributed in the tropical and southern subtropical areas of the globe. In sucrose response threshold assays, foragers of Melipona scutellaris showed an increased responsiveness to sucrose after oral OA treatments. The effect of OA on the bees' responsiveness to sucrose was OA dose-dependent and lasted for up to $1 \mathrm{~h}$. Our results indicate that experimental approaches similar to the ones used for honey bees, Apis mellifera, are feasible for stingless bees. This opens opportunities to study the variability of aminergic regulation of collective behaviour in social bees.
\end{abstract}

\section{Meliponini / biogenic amines / sucrose response threshold / neuropharmacology}

\section{INTRODUCTION}

Biogenic amines play a crucial role in regulating physiological responses and, consequently, the behaviour of animals (Libersat and Pflueger 2004; Farooqui 2012). In invertebrates, they may act as neurotransmitters, neuromodulators, or neurohormones, and affect several physiological levels, such as the central nervous system, the sensory periphery, the motor neurons, and the muscles (Orchard 1982; Roeder 1999; Libersat and Pflueger 2004; Scheiner et al. 2006; Farooqui 2012). Their effect ranges from simple

Corresponding author: M. Hrncir,

michael@ufersa.edu.br

Manuscript editor: Monique Gauthier responses, such as the regulation of an individual's sensitivity to environmental stimuli or of its motivational state, to more complex ones, such as the modulation of associative learning and memory formation (Erber and Kloppenburg 1995; Hammer and Menzel 1998; Bicker 1999; Roeder 1999; Bloch et al. 2000; Scheiner et al. 2002, 2006; Burke et al. 2012).

A particularly interesting animal group for studying the effects of biogenic amines are the eusocial insects, in which modulations of the individuals' behaviour may affect the functioning of the entire colony. Here, behavioural differences among workers are causally linked to differences in their octopamine (OA), dopamine (DA), or serotonin (5-HT) levels (Wagner-Hulme et al. 1999; Schulz et al. 2002; Scheiner et al. 2006; Kamhi and Traniello 2013). The present study is 
the first pharmacological approach to evaluate the influence of $\mathrm{OA}$ in stingless bees (Apidae, Meliponini), a group of highly eusocial bees distributed in the tropical and southern subtropical areas of the globe (Michener 1974; Camargo 2013). In contrast to the honey bee, Apis mellifera L. (Apidae, Apini), most meliponine species occur in rather narrow geographic ranges (Camargo 2013) and show strong species-specific environmental specialisations concerning the organisation of nest-internal activities (e.g. adjustments of the colony reproductive cycle, regulation of the nest climate) and the coordination of nest-external tasks (e.g. defence, food collection) (Michener 1974; Maia-Silva et al. 2014, 2015).

Virtually nothing is known about the physiological underpinning of individual and collective behaviours in stingless bees. In this context, studies of the influence of biogenic amines are particularly important due to their impact on both the individual and the colony level. Until now, however, pharmacological approaches have not been used to understand the functional role of biogenic amines in meliponine bees. The scope of the present study was to evaluate whether experimental procedures to investigate the influence of biogenic amines on individuals similar to those established for honey bees are feasible as well for stingless bees. Given the well-studied effect of OA on reward perception in A. mellifera (Scheiner et al. 2002), we investigated whether, to which extent, and for how long experimentally increased levels of $\mathrm{OA}$ affect the gustatory responsiveness to sucrose in foragers of the stingless bee Melipona scutellaris Latreille, 1811 (Apidae, Meliponini).

\section{MATERIAL AND METHODS}

The present study was performed on the campus of the University of São Paulo at Ribeirão Preto-SP, Brazil. For our experiments, we used two queenright colonies of M. scutellaris that had been established at the university campus 2 years prior to the study. Both colonies contained brood and ample food storage, and were housed in wooden observation nest boxes inside a laboratory building of the biology department, connected to the outside environment by means of plastic tubes trough the laboratory wall that allowed the bees to forage freely. Bees were trained to collect $50 \% \mathrm{w} / \mathrm{w}$ unscented sucrose solution (sucrose $\geq 99.5 \%$, SigmaAldrich ${ }^{\circledR}$, Brazil; no scent added to solution) at an artificial food source at a distance of $5 \mathrm{~m}$ from the nest entrances. As soon as at least five individuals from each colony foraged regularly at the feeder, we captured the arriving foragers individually in glass vials on landing at the food source. The bees were immobilised by chilling on ice (approximately $3 \mathrm{~min}$ ) and, subsequently, harnessed in appropriately cut pipette tips that restrained the body movements but allowed free movement of the antennae and mouthparts (Mc Cabe et al. 2007).

\subsection{Sucrose response threshold (SRT) tests}

After $50 \mathrm{~min}$ in darkness at room temperature (approximately $28{ }^{\circ} \mathrm{C}$ at a relative humidity of approximately $60 \%$ ), we performed gustatory response assays following the sucrose response threshold (SRT) protocol originally established for honey bees (Apis mellifera: Page et al. 1998; Pankiw and Page 2000) and, more recently, successfully adapted for stingless bees (Melipona quadrifasciata and Scaptotrigona aff. depilis: Mc Cabe et al. 2007; Mc Cabe and Farina 2009). The antennae of the harnessed bees were touched with toothpicks imbibed with sucrose solutions of increasing sugar concentration $(0.1,0.3,1,3,10,30$, $50 \% w / w)$. An individual's response to this sucrose stimulus was considered positive only in case it fully extends the proboscis after touching its antennae with the toothpick. Between sucrose stimulations, the bees were tested for their response to pure water in order to control for the potential effects of repeated sucrose stimulations that may lead to either sensitization or habituation, therewith affecting subsequent responses. Individuals that did not respond to any of the sucrose concentrations were excluded from the analysis. To evaluate a bee's sucrose responsiveness during a particular SRT test (see below), we calculated its gustatory response score obtained in the test (GRS = the sum of sugar solutions to which it showed a positive response: GRS $=7$, maximum responsiveness; GRS $=1$, minimum responsiveness; bees with GRS $=0$ excluded from analysis).

\subsection{Experiment 1 - concentration effect}

First, we evaluated the effect of different OA concentrations on the foragers' sucrose responsiveness. For 
this, the harnessed bees were allocated in four experimental groups. On each day of experiment, we assigned approximately equal numbers of foragers to each experimental group. After an initial SRT test, the foragers were fed with $5 \mu \mathrm{L}$ of $50 \% w / w$ sucrose solution (sucrose $\geq 99.5 \%$ : Sigma-Aldrich $\AA$, Brazil) containing different doses of OA (Sigma-Aldrich ${ }^{\circledR}$, Brazil): (i) no OA (control group, $\mathrm{CO} ; n=37$ bees), (ii) $9.5 \mu \mathrm{g}$ OA (0.01 M; $n=37$ bees), (iii) $19 \mu \mathrm{g}$ OA ( $0.02 \mathrm{M} ; n=43$ bees), (iv) $38 \mu \mathrm{g} \mathrm{OA}(0.04 \mathrm{M} ; n=41$ bees). All oral treatments were performed using used calibrated precision syringes (Hamilton ${ }^{\circledR}$ syringe $75 \mathrm{~N}$, volume $5 \mu \mathrm{L}$ : Sigma-Aldrich $®$, Brazil). Thirty minutes after feeding, the foragers' responsiveness to sucrose was tested again. Thus, for each individual, we obtained two GRS, one before and one after the oral OA treatment.

\subsection{Experiment 2-time effect}

In a second assay, we investigated temporal changes concerning the effect of oral OA treatments on the foragers' sucrose responsiveness. After an initial SRT test, we fed $5 \mu \mathrm{L}$ of $50 \% \mathrm{w} / \mathrm{w}$ sucrose solution (sucrose $\geq 99.5 \%$, Sigma-Aldrich ${ }^{\circledR}$, Brazil) to the harnessed bees. The sucrose solution was either pure (control group, $\mathrm{CO} ; n=34$ bees) or contained $9.5 \mu \mathrm{g}$ OA (experimental group, OA; $n=37$ bees). This OA dose was chosen owing to its significant effect on the SRT of $M$. scutellaris foragers (experiment 1) and based on a similar experimental series in honey bees, in which the same OA concentration (0.01 M) had been applied (Pankiw and Page 2003). The response of both groups was tested repeatedly $30,45,60$, and $75 \mathrm{~min}$ after the oral treatments.

\subsection{Statistical analysis}

In order to assess the effect of different OA concentrations on the sucrose responsiveness of $M$. scutellaris (experiment 1), each experimental group $(\mathrm{CO}, 9.5 \mu \mathrm{g}$, $19 \mu \mathrm{g}, 38 \mu \mathrm{g}$ OA) was evaluated concerning potential changes in the individuals' GRS using Wilcoxon signedrank tests (pairwise comparison: GRS before vs. after oral treatment). Changes in sucrose responsiveness (GRS) over time after oral OA treatments (experiment 2) were analysed using two-way repeated measures ANOVA (Tukey's test for post hoc pairwise comparison), with treatment (CO vs. OA) and time of the SRT test $(0-75 \mathrm{~min})$ as predictors for the observed variation in gustatory responsiveness to sucrose. In both experiments, we excluded bees that did not respond to any of the sucrose concentrations from the analysis. Statistical tests (Wilcoxon Signed Rank Test, Two Way Repeated Measures ANOVA) were performed using the analysis software SigmaPlot 12.5 (Systat Software Inc., USA). The $\alpha$-level of statistical significance was $P \leq 0.05$.

\section{RESULTS}

\subsection{Dose-dependent effect of $\mathrm{OA}$ on sucrose responsiveness of $M$. scutellaris}

Octopamine had a dose-dependent effect on sucrose responsiveness. The foragers' gustatory responsiveness to sucrose increased significantly after the ingestion of OA (Figure 1a). In contrast to bees from the control group (CO), OA-treated foragers showed higher gustatory response scores (GRS) after receiving the biogenic amine than before the respective oral treatment. This effect was significant for the experimental groups that had been fed with 9.5 and $19 \mu \mathrm{g}$ OA. However, at the highest OA dose $(38 \mu \mathrm{g})$, the observed increase in the bees' GRS was not statistically significant (Wilcoxon signed-rank test; CO: $W=68$, $n=37$ bees, $P=0.455$; OA $9.5 \mu \mathrm{g}: W=166$, $n=37$ bees, $P=0.043$; OA $19 \mu \mathrm{g}: W=311$, $n=43$ bees, $P=0.001$; OA $38 \mu \mathrm{g}$ : $W=141$, $n=41$ bees, $P=0.070$ ).

\subsection{Time-dependent effect of $\mathrm{OA}$ on sucrose responsiveness of $M$. scutellaris}

The effect of octopamine on the gustatory responsiveness to sucrose changed over time. Whereas foragers from the control group (CO) maintained a stable SRT level along the assay, bees from the experimental group showed significantly increased sucrose responsiveness up to $1 \mathrm{~h}$ after the oral OA treatment. OA-treated bees tested 30 and $45 \mathrm{~min}$ after feeding showed the greatest effect and the most significant difference to bees from the control group. The effect of OA decreased after $60 \mathrm{~min}$, and wore off completely after $75 \mathrm{~min}$ (two-way repeated measures ANOVA: factor treatment [CO vs. OA]: $F=51.9, P<0.001$; factor time [0-75 min]: $F=26.4, P<0.001$; factor treatment $\times$ time: $F=29.9, P<0.001$; Tukey's test for pairwise multiple comparison) (Figure 1b). 
a

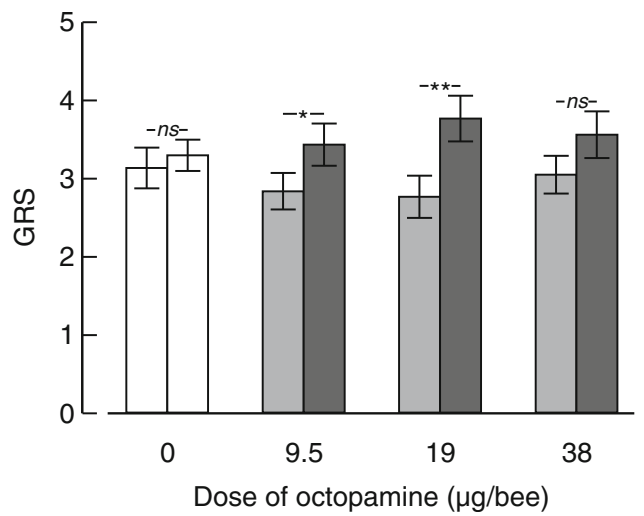

b

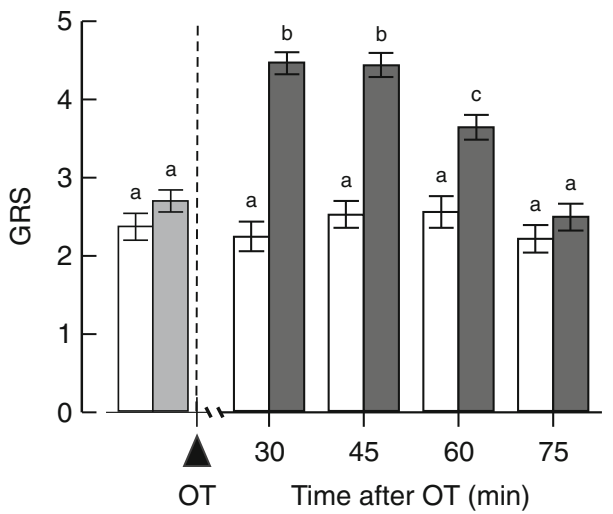

Figure 1. Effect of oral OA treatment on sucrose responsiveness in Melipona scutellaris. Given are mean values \pm SE of gustatory response scores (GRS). a GRS of foragers before (left aligned bars ) and after (right aligned bars) feeding $5 \mu \mathrm{L}$ of sucrose solution containing different doses of OA $0 \mu \mathrm{g}$ (pure sucrose solution; $n=37$ bees), $9.5 \mu \mathrm{g}$ ( $0.01 \mathrm{M} ; n=37$ bees), $19 \mu \mathrm{g}(0.02 \mathrm{M} ; n=43$ bees), $38 \mu \mathrm{g}(0.04 \mathrm{M} ; n=41$ bees). Asterisks indicate significant differences between GRS test phases (Wilcoxon signed-rank test: $n s, P>0.05 ; * P<0.05$, $* * P<0.005$ ). b GRS of foragers before as well as $30,45,60$, and 75 min after oral treatment (OT, dashed line) with $5 \mu \mathrm{L}$ of pure sucrose solution (white bars, $n=34$ bees) or $5 \mu$ l of sucrose solution containing $9.5 \mu \mathrm{g}$ OA (grey bars, $n=37$ bees). Different superscript letters indicate significant differences between groups (two-way repeated measures ANOVA, Tukey's test: $P<0.05)$.

\section{DISCUSSION}

The present study is the first pharmacological approach evaluating the effect of biogenic amines on the behaviour of stingless bees (Apidae, Meliponini), demonstrating significant behavioural changes in foragers of $M$. scutellaris after the ingestion of octopamine (OA). Moreover, it indicates that these bees can be successfully used in neuropharmacological assays that involve complex and temporally extensive behavioural procedures in the laboratory. Stingless bees are a group of highly eusocial bees comprising more than 500 mainly tropical species (Camargo 2013). Neotropical species, in particular, show a remarkable diversity concerning life style and ecology (Michener 1974; Barth et al. 2008; Hrncir 2009; Jarau 2009; Hrncir and Maia-Silva 2013). Thus, they offer an excellent opportunity to investigate the relationship between ecological constraints and the evolution of behavioural adaptations on both the individual and colony level as well as of the underlying physiological mechanisms.

Neurophysiologically, the behavioural organisation and coordination of social insect colonies is based on modulations of the individuals' responsiveness to task-specific stimuli through biogenic amines like OA, dopamine (DA), or serotonin (5-HT) (Schulz et al. 2002; Scheiner et al. 2006; Kamhi and Traniello 2013). In honey bees, A. mellifera, the modulating effect of these neurochemicals has frequently been assessed through feeding biogenic amines dissolved in sucrose solution (e.g.,: Schulz and Robinson 2001; Scheiner et al 2002; Barron et al. 2002, 2007; Pankiw and Page 2003). This simple and non-invasive method has been shown to result in a dose-dependent increase of the concentration of the respective neurochemical in the bees' brain (Schulz and Robinson 2001) and, therefore, provides a powerful tool to investigate the functional role of biogenic amines.

The results of our study demonstrate that a single oral treatment with OA was sufficient to increase the responsiveness of $M$. scutellaris to sucrose stimuli. In line with similar findings for A. mellifera (Scheiner et al. 2002; Pankiw and Page 2003), the observed increase in sucrose responsiveness was OA dose-dependent and 
measurable for up to $60 \mathrm{~min}$. In honey bees, OA doses of 1.9 and $19 \mu \mathrm{g}$ were found to significantly enhance the bees' responsiveness to sucrose (Scheiner et al. 2002; Pankiw and Page 2003). In line with these findings, the ingestion of 9.5 and $19 \mu \mathrm{g}$ OA resulted in a significant increase in gustatory responsiveness of $M$. scutellaris. This enhancing effect, however, declined at the highest OA dose of $38 \mu \mathrm{g}$. Several factors might be responsible for this decrease in effect at the highest concentration. Studies on honey bees point to complex dose-response relationships for biogenic amines (Scheiner et al. 2002). Here, U shaped dose-response functions, similar to that found in the present study, may be due to the fact that an excess of OA antagonises its effect under physiological concentrations (Scheiner et al. 2006). Alternatively, the differential effect of low versus high OA doses may be explained through the participation of different intracellular signalling pathways depending on OA concentration (Papaefthimiou and Theophilidis 2011; Huang et al. 2012).

Although it is not clear yet, how fed biogenic amines reach the respective brain areas in which they induce modulatory effects (Scheiner et al. 2006), oral OA treatments have been shown to increase the OA brain levels in honey bees (Schulz and Robinson 2001). These increasing endogenous OA levels and correlated increasing gustatory responsiveness (Pankiw and Page 2003) are associated with the workers' transition from hive-internal tasks to foraging (Schulz and Robinson 1999, 2001; Wagner-Hulme et al. 1999; Barron et al. 2002; Schulz et al. 2002; Barron and Robinson 2005). However, the aminergic modulation of temporal polyethism in social insects is not restricted to a single biogenic amine. In $A$. mellifera, in addition to OA, 5-HT and DA vary with development and differ among workers executing different tasks, suggesting the involvement of these neuromodulators in the bees' temporal polyethism (Harris and Woodring 1992; Taylor et al. 1992; Bozic and Woodring 1998; Schulz and Robinson 1999).

Given the similarities of the effect of OA on the sucrose responsiveness in A. mellifera and M. scutellaris, this biogenic amine could be as well a key molecule for modulating the division of labour in stingless bee colonies. This assumption, however, implies a natural variation in OA brain titres between bees performing different tasks. An important next step, therefore, will be the quantification of the endogenous biogenic amine levels in M. scutellaris and other meliponine species, in order to investigate whether OA has a common functional role among highly eusocial bees. In any case, our study shows that similar experimental approaches as the ones used for A. mellifera are feasible for stingless bees. This, on the one hand, opens opportunities to study the variability and, eventually, the evolution of aminergic regulation of collective behaviour in social bees. On the other hand, the possibility to use similar experimental approaches facilitates comparative studies among eusocial bees concerning the effect of environmental stressors on physiological responses of individuals, frequently involving stress-induced changes in biogenic amine titres (Davenport and Evans 1984; Harris and Woodring 1992; Even et al. 2012; Farooqui 2012). Here, the impact of pesticides, particularly of neonicotinoids and formamidines, on bee behaviour has become a hot topic in recent years owing to the suspected contribution of these neurotoxins to the worldwide loss of pollinators (Farooqui 2013; van der Sluijs et al. 2013). Both neonicotinoids and formamidines mimic the action of biogenic amines (Evans and Gee 1980; Matsuda et al. 2001). Consequently, the chronic exposure of bees to sublethal doses of these substances may lead to critical modifications of neural signalling and, eventually, cause behavioural dysfunctions (Farooqui 2013), such as a reduction of respiration rate and flight activity (M. quadrifasciata: Tomé et al. 2015), an impairment of olfactory learning and memory, or a decreasing gustatory responsiveness (A. mellifera: Mengoni Goñalons and Farina 2015). Given these interactions between pesticides, biogenic amine signalling, and bee behaviour, the results of our study provide an important baseline for future studies on this topic in stingless bees. 


\section{ACKNOWLEDGMENTS}

We thank Ronaldo Zucchi for providing the necessary laboratory facilities and two anonymous reviewers for valuable comments and suggestions. This work was supported by grants of the Argentinian Science Foundations CONICET (Consejo Nacional de Investigaciones Científicas y Técnicas) under grant PIP11220110100472, and ANPCYT (Agencia Nacional de Promoción Científica y Tecnológica) under grant PICT-2013-1060, and the University of Buenos Aires under grant UBACYT20020130100185BA to Walter M. Farina, and by the Brazilian Science Foundations FAPESP (Fundação de Amparo à Pesquisa do Estado de São Paulo) under grant 2006/50809-7, and CNPq (Conselho Nacional de Desenvolvimento Científico e Tecnológico) under grants 304722/2010-3, and 309914/2013-2 to Michael Hrncir.

Effets temporels et dépendant de la dose de I' octopamine administrée oralement chez les abeilles sans aiguillon (Melipona scutellaris)

Meliponini / amines biogènes / seuil de réponse au sucrose / neuropharmacologie

Dosis -und zeitabhängige Effekte einer oralen Octopamin-Applikation auf die Ansprechempfindlichkeit gegenüber Saccharose bei stachellosen Bienen (Melipona scutellaris )

Meliponinen / biogene Amine / Saccharose Reaktionsschwellenwert / Neuropharmakologie

\section{REFERENCES}

Barron, A.B., Robinson, G.E. (2005) Selective modulation of task performance by octopamine in honey bee (Apis mellifera ) division of labour. J. Comp. Physiol. A. 191, 659-668

Barron, A.B., Schulz, D.J., Robinson, G.E. (2002) Octopamine modulates responsiveness to foragingrelated stimuli in honey bees (Apis mellifera). J. Comp. Physiol. A. 188, 603-610

Barron, A.B., Maleszka, R., Vander Meer, R.K., Robinson, G.E. (2007) Octopamine modulates honey bee dance behavior. Proc. Natl. Acad. Sci. U. S. A. 104, 1703-1707

Barth, F.G., Hrncir, M., Jarau, S. (2008) Signals and cues in the recruitment behavior of stingless bees (Meliponini). J. Comp. Phsyiol. A 194, 313-327

Bicker, G. (1999) Biogenic amines in the brain of the honeybee: cellular distribution, development, and behavioral functions. Microsc. Res. Tech. 44, 166-178
Bloch, G., Simon, T., Robinson, G.E., Hefez, A. (2000) Brain biogenic amines and reproductive dominance in bumble bees (Bombus terrestris ). J. Comp. Physiol. A. 186, 261-268

Bozic, J., Woodring, J. (1998) Variations of brain biogenic amines in mature honeybees and induction of recruitment behavior. Comp. Biochem. Physiol. A 120, 737-744

Burke, C.J., Huetteroth, W., Owald, D., Perisse, E., Krashes, M.J., Das, G., Gohl, D., Silies, M., Certel, S., Waddell, S. (2012) Layered reward signalling through octopamine and dopamine in Drosophila . Nature $492,433-437$

Camargo, J.M.F. (2013) Historical biogeography of the Meliponini (Hymenoptera, Apidae, Apinae) of the neotropical region. In: Vit, P., Pedro, S.R.M., Roubik, D.W. (eds.) Pot-honey: a legacy of stingless bees, pp. 19-34. Springer Science and Business Media, New York

Davenport, A.P., Evans, P.D. (1984) Stress-induced changes in the octopamine levels of insect haemolymph. Insect Biochem. 14, 135-143

Erber, J., Kloppenburg, P. (1995) The modulatory effects of serotonin and octopamine in the visual system of the honey bee (Apis mellifera L.): I. Behavioral analysis of the motion-sensitive antennal reflex. J. Comp. Physiol. A. 176, 111-118

Evans, P.D., Gee, J.D. (1980) Action of formamidine pesticides on octopamine receptors. Nature 287, 60-62

Even, N., Devaud, J.M., Barron, A.B. (2012) General stress responses in the honey bee. Insects 3, 1271-1298

Farooqui, T. (2012) Review of octopamine in insect nervous systems. Open Access Insect Physiol. 4, 1-17

Farooqui, T. (2013) A potential link among biogenic amines-based pesticides, learning and memory, and colony collapse disorder: a unique hypothesis. Neurochem. Int. 62, 122-136

Hammer, M., Menzel, R. (1998) Multiple sites of associative odor learning as revealed by local brain microinjections of octopamine in honeybees. Learn. Mem. 5, 146-156

Harris, J.W., Woodring, J. (1992) Effects of stress, age, season, and source colony on levels of octopamine, dopamine and serotonin in the honey bee (Apis mellifera ) brain. J. Insect Physiol. 38, 29-35

Hrncir, M. (2009) Mobilizing the foraging force - mechanical signals in stingless bee recruitment. In: Jarau, S., Hrncir, M. (eds.) Food exploitation by social insects - ecological, behavioral, and theoretical approaches, pp. 199-221. CRC Press Taylor \& Francis Group, Boca Raton

Hrncir, M., Maia-Silva, C. (2013) On the diversity of foraging-related traits in stingless bees. In: Vit, P., Pedro, S.R.M., Roubik, D.W. (eds.) Pot-honey - a legacy of stingless bees, pp. 201-215. Springer Science and Business Media, New York

Huang, J., Wu, S.F., Li, X.H., Adamo, S.A., Ye, G.Y. (2012) The characterization of a concentrationsensitive $\alpha$-adrenergic-like octopamine receptor found on insect immune cells and its possible role in mediating stress hormone effects on immune function. Brain Behav. Immun. 26, 942-950 
Jarau, S. (2009) Chemical communication during food exploitation in stingless bees. In: Jarau, S., Hrncir, M. (eds.) Food exploitation by social insects - ecological, behavioral, and theoretical approaches, pp. 223-249. CRC Press Taylor \& Francis Group, Boca Raton

Kamhi, J.F., Traniello, J.F.A. (2013) Biogenic amines and collective organization in a superorganism: neuromodulation of social behavior in ants. Brain Behav. Evol. 82, 220-236

Libersat, F., Pflueger, H.J. (2004) Monoamines and the orchestration of behavior. Bioscience 54, 17-25

Maia-Silva, C., Imperatriz-Fonseca, V.L., Silva, C.I., Hrncir, M. (2014) Environmental windows for foraging activity in stingless bees, Melipona subnitida Ducke and Melipona quadrifasciata Lepeletier (Hymenoptera: Apidae: Meliponini). Sociobiology 61, 378-385

Maia-Silva, C., Hrncir, M., Silva, C.I., Imperatriz-Fonseca, V.L. (2015) Survival strategies of stingless bees (Melipona subnitida) in an unpredictable environment, the Brazilian tropical dry forest. Apidologie 46, 631-643

Matsuda, K., Buckingham, S.D., Kleier, D., Rauh, J.J., Grauso, M., Sattelle, D.B. (2001) Neonicotinoids: insecticides acting on insect nicotinic acetylcholine receptors. Trends Pharmacol. Sci. 22, 573-580

Mc Cabe, S.I., Farina, W.M. (2009) Odor information transfer in the stingless bee Melipona quadrifasciata: effect of in-hive experiences on classical conditioning of proboscis extension. J. Comp. Physiol. A. 195, 113-122

Mc Cabe, S.I., Hartfelder, K.H., Santana, W.C., Farina, W.M. (2007) Odor discrimination in classical conditioning of proboscis extension in two stingless bee species in comparison to Africanized honeybees. J. Comp. Physiol. A. 193, 1089-1099

Mengoni Goñalons, C.M., Farina, W.M. (2015) Effects of sublethal doses of imidacloprid on young adult honeybee behaviour. PLoS One 10, e0140814

Michener, C.D. (1974) The social behavior of the bees $-\mathrm{a}$ comparative study. The Belknap Press of Harvard University Press, Cambridge-MA

Orchard, I. (1982) Octopamine in insects: neurotransmitter, neurohormone, and neuromodulator. Can. J. Zool. 60, 659-669

Page, R.E., Erber, J., Fondrk, M.K. (1998) The effect of genotype on response thresholds to sucrose and foraging behavior of honey bees (Apis mellifera L.). J. Comp. Physiol. A. 182, 489-500
Pankiw, T., Page, R.E. (2000) Response threshold to sucrose predict foraging division of labor in honeybees. Behav. Ecol. Sociobiol. 47, 265-26

Pankiw, T., Page, R.E. (2003) Effect of pheromones, hormones, and handling on sucrose response thresholds of honey bees (Apis mellifera L.). J. Comp. Physiol. A. 189, 675-684

Papaefthimiou, C., Theophilidis, G. (2011) Octopamine-a single modulator with double action on the heart of two insect species (Apis mellifera macedonica and Bactrocera oleae ): acceleration vs. inhibition. J. Insect Physiol. 57, 316-325

Roeder, T. (1999) Octopamine in invertebrates. Prog. Neurobiol. 59, 533-561

Scheiner, R., Plückhahn, S., Öney, B., Blenau, W., Erber, J. (2002) Behavioural pharmacology of octopamine, tyramine and dopamine in honey bees. Behav. Brain Res. 136, 545-553

Scheiner, R., Baumann, A., Blenau, W. (2006) Aminergic control and modulation of honeybee behaviour. Curr. Neuropharmacol. 4, 259-276

Schulz, D., Robinson, G.E. (1999) Biogenic amines and division of labor in honey bee colonies: behaviorally related changes in the antennal lobes and age-related changes in the mushroom bodies. J. Comp. Physiol. A. 184, 481-488

Schulz, D., Robinson, G.E. (2001) Octopamine influences the division of labor in honey bee colonies. J. Comp. Physiol. A. 187, 53-61

Schulz, D.J., Barron, A.B., Robinson, G.E. (2002) A role for octopamine in honey bee division of labor. Brain Behav. Evol. 60, 350-359

Taylor, D.J., Robinson, G.E., Logan, B.J., Laverty, R., Mercer, A.R. (1992) Changes in brain amine levels associated with the morphological and behavioral development of the worker honeybee. J. Comp. Physiol. A. 170, 715-721

Tomé, H.V.V., Barbosa, W.F., Martins, G.F., Guedes, R.N.C. (2015) Spinosad in the native stingless bee Melipona quadrifasciata: Regrettable non-target toxicity of a bioinsecticide. Chemosphere 124, 103-109

van der Sluijs, J.P., Simon-Delso, N., Goulson, D., Maxim, L., Bonmatin, J.M., Belzunces, L.P. (2013) Neonicotinoids, bee disorders and the sustainability of pollinator services. Curr. Opin. Environ. Sustain. 5, 293-305

Wagner-Hulme, C., Kuehn, J.C., Schulz, D.J., Robinson, G.E. (1999) Biogenic amines and division of labor in honey bee colonies. J. Comp. Physiol. A. 184, 471-479 